\title{
Resource Industries in the Post-Industrial City
}

DANIEL ADAMS \& MARIE LAW ADAMS

Northeastern University

Resource industries are present in the post-industrial city in a mutable state, as the goods of global trade pass through as interim piles (salt, sand, and gravel), in holding tanks (petroleum), and silos (cement). The flow of resources is fundamental to urban life and shapes the urban landscape, yet engagement with this mode of industry in the city has been largely outside the realm of the design disciplines.

If Reyner Banham's Los Angeles was made legible through the mediating lens of the windshield and the rear-view mirror, then the constructed landscapes of primary resources in today's post-industrial city are only understandable through the windshield of the front-end loader that acts as the mediator between global networks and local distribution. The material terminals that these loaders serve are not classified by permanent structures, but rather by the throughput dictated by the demands of the city.

This dynamic relationship of primary industry to the contemporary city is better understood through the relational terms of ecology than formal conventions of architecture. As such, the environments created by the flows of primary industry to urban centers require new modes of engagement from designers. The current architectures of such resource industries in cities- containers, sheds, fences - result from practices of use-based zoning, homeland security, and offsite mitigation, but such static structures fail to engage the dynamic dimensions of a fluid industry. In order to create a new framework, this paper analyzes the spatial and programmatic opportunities that result from re-conceiving these three regulatory conventions through an analysis of a realized project with a global marine terminal in Boston Harbor.
INVISIBLE GIANTS

The Atacama Desert in Northern Chile is dually famous for its inhospitable character for human settlement, and its tremendous importance to contemporary urbanism and industrialization. This hyper arid environment, almost totally lacking in precipitation, is often characterized as the driest desert on earth. From this hyper aridity, arises an almost equivalent hyper purity of minerals. Cities themselves do not appear in the desert. Instead, the desert is characterized by the mines, evaporation pools, and ports, that extract and produce the seemingly intangible material industries that ultimately flow through and fuel distant cities

Desert salars, mineral deposits resulting from geologic events, are mined for salt used for chemical industries, food production and roadway deicing in distant cities. In these desert salars, the changing physical form of the landscape makes legible the material demands of far off cities. As it snows in New York City or Boston, United States, the open pit mines grow in Chile. For example, the image below shows the moment when 1,000,000 tons of salt had been excavated from the salar, an amount equivalent to Massachusetts' yearly consumption for road de-icing. The unique opportunity to observe the collective consumption of Massachusetts becomes possible in this captured moment. The Atacama salars are a landscape where collective impacts of industry become tangible and communicative in the landscape.

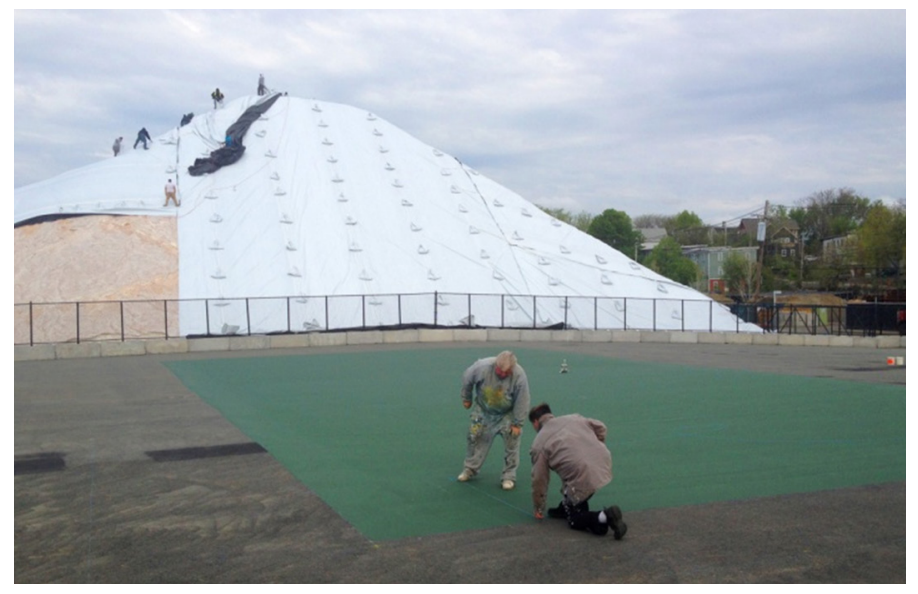

FIgure 1: 1,000,000 tons of excavated salt. Atacama desert, Chile 
In contrast, the cold states of the United States operate under a 'bare pavement policy', a term used to describe the management policy for responding to snow and ice. This policy enforces the erasure of snow and ice from road surfaces. Salt is distributed on roadways in advance of winter weather events. The salt dissolves into the snow and ice changing its chemistry from freshwater to a salty brine, and lowering the freezing point of the water so that snow and ice never form on the ground and the salty brine simply washes away. Ultimately, the salt, which was encrusted for thousands of years on the desert surface of Chile, passes through for only minutes on city streets, its material presence nearly illegible. At no moment in time is Massachusetts' annual consumption of $1,000,000$ tons of salt ever specifically legible. The material flows imperceptibly through the city, passing briefly through docks, temporary stockpiles, truck trailers, spreaders, dissolved on city streets, through catch basins and pipes to outfalls into rivers, harbors and the ocean.

In 1995, Canadian Economist Brewster Kneen described the Cargill corporation as an 'Invisible Giant', a massive private industry operating across the world, out of sight and out of mind from even the consumers of Cargill's products (1). Kneen's use of the term Invisible Giant referenced not only Cargill's operations as a multinational corporation but also the character of the food commodities that the company traded. The term Invisible Giants can also be used to describe the massive material flows that pass through a city, nearly un-noticed, their full quantity never presented nor legible, even as they participate in the construction and maintenance of the urban landscape. While materials such as salt, gypsum, heating oil, asphalt, and gravel make up the structures of the city, their immediate physical form is ephemeral.

The extraction landscapes of these materials are geographically divorced from their ultimate use in the city. While it is possible to stand on the edge of a pit in Chile and visualize New York City's or the state of Massachusetts' consumption of salt, how is this same legibility and understanding afforded in the city itself? In light of

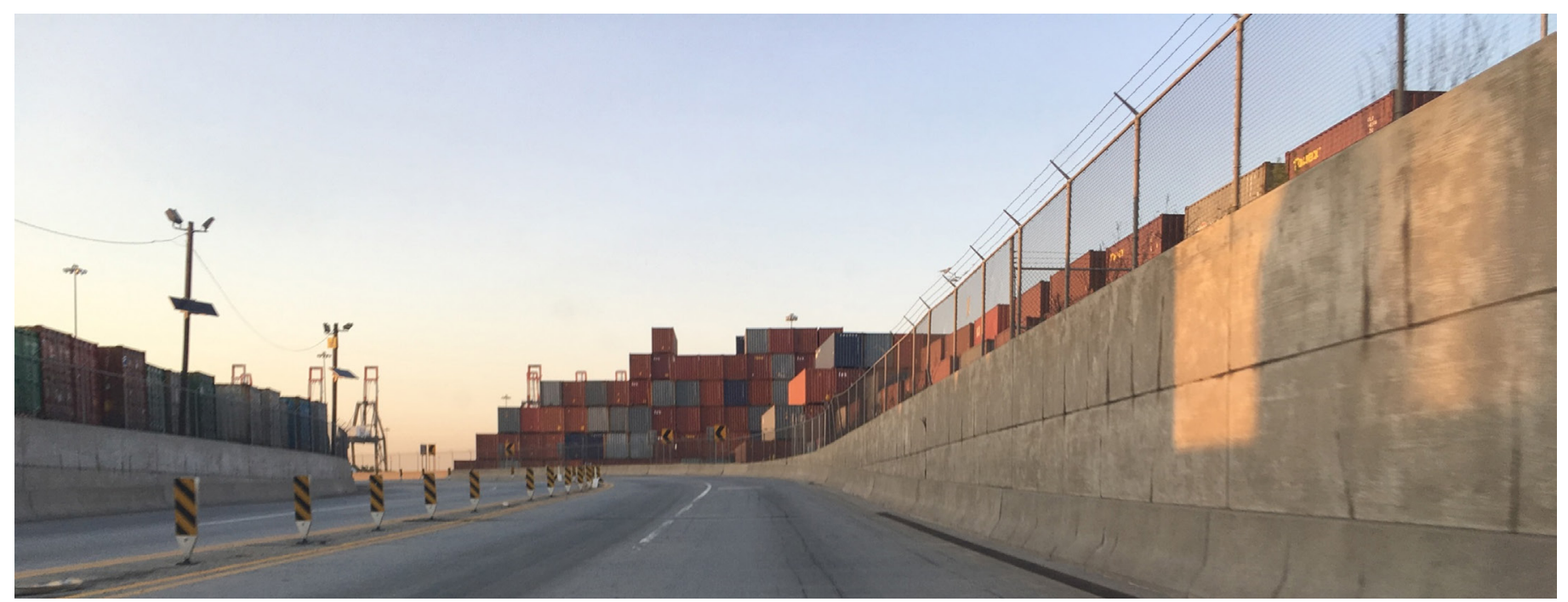

the growing urgency for cities to become less consumptive or more intelligent in their management of global resources and material flows- how are cities today designed to engage with their own material footprints?

\section{METROPOLITAN CONSCIOUSNESS}

In the book 'Fish Story', Allan Sekula discusses containerization as a critical infrastructure that contributes to the loss of legibility of industry and material consumption in cities. "If steam was the victory of the straight line over the zigzags demanded by the wind, containerization was the victory of the rectangular solid over the messy contingency of the Ark. As we will see, containerization obscures more than the physical heterogeneity of cargoes, but also serves to make ports less visible and more remote from metropolitan consciousness."(2)

Sekula highlights the shipping container as a device that not only increases the regularization and expedience of loading and unloadinghandling logistics- but also eliminates the particularities and nuances of the transported cargos. Whereas one was once exposed to the particularities of cargo held within sacks, barrels and crates- whether it leaked, smelled, or was oddly shaped or textured- these perceptions are overwhelmed by the regularity of the container.

However, Sekula is not only describing the specific character of the shipping container itself but the urban relationships that result from the artifact. By increasing and regularizing the expedience of the handling, less people and therefore oversight are required. Even an empty 40 foot shipping container weighs 8000 pounds,

precluding any handling without the assistance of machines. Likewise, a standard Panamax vessel, servicing cities like New York City or Boston, can be loaded with as many as 2,500 shipping containers, which requires a massive amount of matching onshore land to discharge and sort the cargo. Each dimensional parameter that creates massive weights and areas tend to dislocate people and urban development away from these operations. These critical points of industrial

Figure 2: Container terminal at the Port of New York/New Jersey, Newark, NJ 
exchange, where global material trade and consumption could be most legible, become relegated outside of cities and away from the metropolitan consciousness identified by Sekula.

Containerization is a specific example in a larger trend of architecture and infrastructure that isolate and hide the material footprints and resource consumption of cities from everyday urban life. Containers, much like the sheds, fences, and buffer landscapes, mentioned earlier, are the architectural manifestations of outmoded regulatory practices that shape the relationship between industry and the city.

\section{USE BASED ZONING}

Industrial operations are highly varied based on the particularities of their operations and the material that they handle or produce, yet, the conventions of use based zoning in the United States largely treat the category of 'industry' as a monolithic entity. For example, in most city zoning ordinances a marine industrial road salt dock, scrap metal yard, and a liquefied natural gas (LNG) terminal would all fall into a general category of heavy industry, despite significant differences in the security, public health risk, environmental impacts and specific material character of the product. The generalized definition

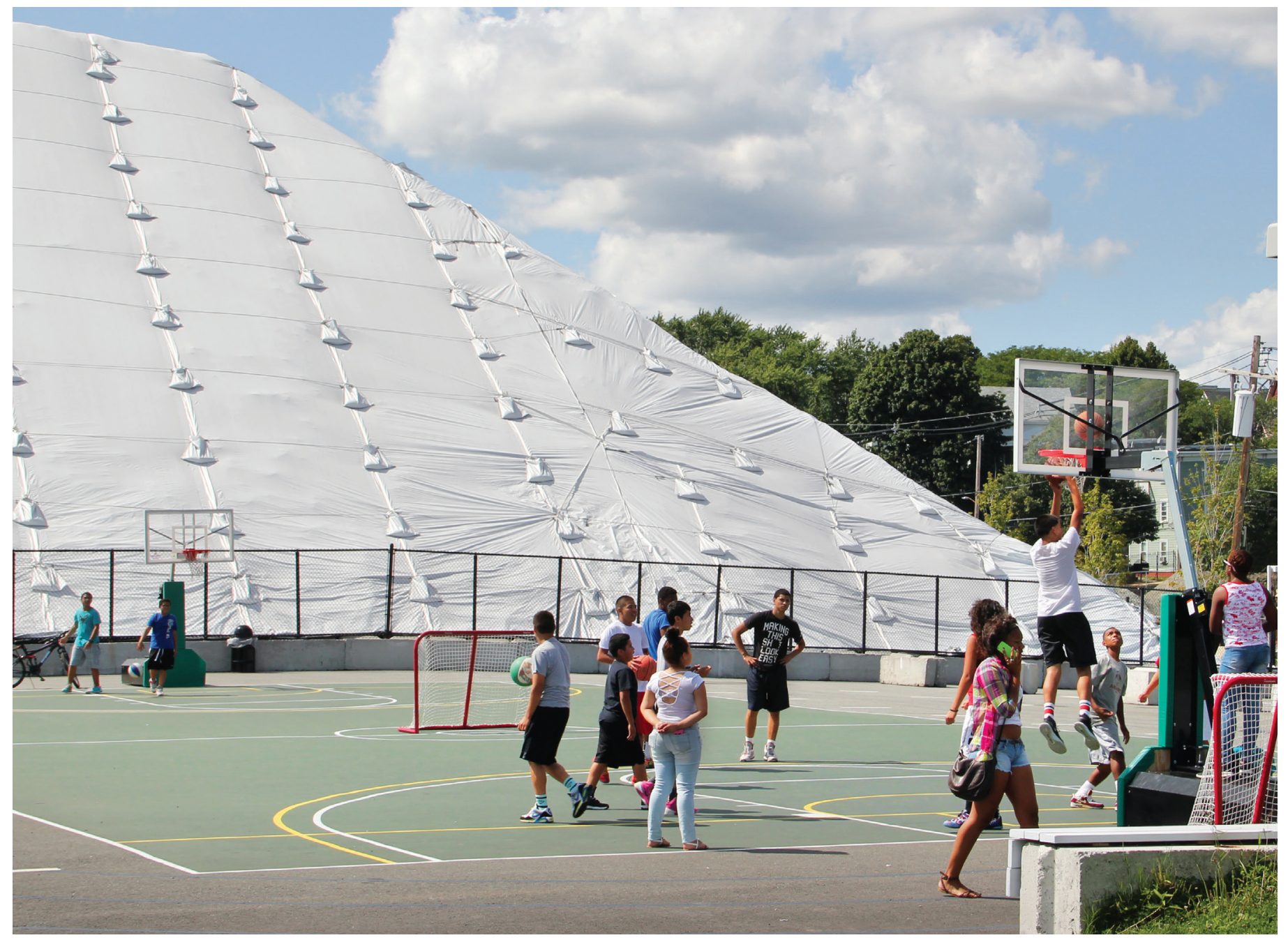

and 'catch-all' grouping of such operations engenders regulations based on lowest common denominator parameters of the industries that overlook and prevent designing for inherent opportunities and nuances that exist within one industry versus another.

Similarly, industrial operations are often homogeneously characterized despite the reality that the industrial operations are often highly varied. As a consequence, particular qualities that could be considered for other forms of urban engagement are precluded. Nearly any marine industrial terminal, for scrap metal, salt, or containers will inevitably have a variety of internal operations involving office workers, mechanics and welding shops for machine repairs, and junkyards, in addition to the areas specifically dedicated to berthing of marine vessels and the stockpiling of cargos. But despite the inherent variability of these areas, such operations are uniformly classified as industry.

Another type of variability is often built into the physical industrial landscape itself. Shrouded beneath seemingly homogenous carpets of asphalt are accumulations of past and present infrastructures and industrial uses. These variables are also overlooked by single use zoning practices. A typical example is the constructed nature of the 
water's edge, which is often built for different purposes and therefore embedded with different potentials for types of uses.

The Rock Chapel Marine terminal in Chelsea, Massachusetts presents an alternative by partnering programs with specific landscape and infrastructure characteristics in the ground. In its previous use as an oil terminal, a portion of the six acre waterfront terminal was built as a steel sheet pile bulkhead used for berthing oil barges. At another area of the terminal, where barges were not moored, the shoreline was armored with riprap used to retain soil and resist the weight of oil tanks.

In transforming this site to a new use, the potentials of each of these shoreline types to support industrial or recreation or habitat uses was analyzed, and highly varied programs, including truck dispatching, cargo offloading and stockpiling, public access recreation, and habitat planting areas, were positioned accordingly. The steel bulkhead was preserved to function for mooring deep water vessels, whereas the riprap shoreline allows a safer, more gradual transition to the water which can support types of intertidal habitat that are prohibited by steel bulkheads, such as soft shell clam habitat and Spartina grass installations. Public access recreation was similarly positioned in the areas adjacent to rip-rap shoreline, creating a safer edge for access to the waterway.

Another example of the embedded conditions of such inner harbor industrial sites is the nearly ubiquitous presence of utility infrastructures for cable, pipe, and conduit crossing under water. These utility easements run nearly undetected through waterfront industrial terminals, but present specific limitations for the surface use of the landscape-such as prohibiting stockpiling of materials and related surcharging or the construction of structures above that prevent maintenance access. As a result, these easements create zones that prohibit industrial activities but can instead be reconsidered for other uses. Such easements can occupy acres of land surface but are often included within the industrial zoning category, even though nearly every form of industrial use is prohibited by the sub-surface infrastructure.

At Rock Chapel Marine, public recreation access was developed on the working waterfront over the surface of such utility easement locations. By pairing recreation with these easements, dynamic relationships and overlaps are created, where industrial and everyday life intermingles.

One of the consequences of typical use based zoning is the lack of customization to particular types of industrial operations, wherein LNG and salt are regulated by the same zoning parameters. All industrial operations have particularities and nuances that present specific opportunities for design response. For instance, the de-icing salt industry operates seasonally- highly active in the winter and nearly dormant in the summer.

This unique annual cycle creates the opportunity for seasonal reinhabitation by other uses, like hardscape recreation and public event space. In cold climates, the opposing cycles of winter de-icing with salt and outdoor summer recreation is nearly a perfect pairing. Such seasonal partnership would not necessarily be found in other types of industries, yet the monolithic and singularizing practices of standard zoning codes prohibits this form of layered programming.

\section{HOMELAND SECURITY}

A second regulatory convention that frames the relationship of industry to the city is homeland security. Here again, marine terminals are often monolithically designated as homeland security zones that require an 8 foot tall fence around their full perimeter, thereby creating a major obstacle for urban engagement. In such security zones, access is reserved for TWIC (Transportation Worker Identification Credential) card holders only - essentially prohibiting any form of public access. The TWIC final rule was published in 2007, and requires individuals to pass a security threat assessment and provide fingerprints and personal biographic information to be allowed access to secured regions of the waterfront.

Just as singular zoning techniques negate or subsume the particularities of industrial operations, many operations on industrial terminals do not require specific security protocols, and the security zone can be largely minimized, allowing for a more flexible occupation of other areas on the terminal. At salt docks, the benign nature of the product and its operations exclude it from being a large security concern, so on such sites, the security perimeter can be significantly reduced to the ship's gangway access and the required area for a security guard to monitor ship lines, which typically accounts for only a small percentage of the terminal's overall area.

Similarly, such security protocols are often only applicable to specific activities that occur at specific times. For example, at a salt dock, only the ship berthing is under the jurisdiction of homeland security, not the everyday trucking operations. In this case, homeland security focuses on monitoring for illegal entry into the country by stowaways and the transfer of illegal goods through international imported cargos. However, such berthing activities are often temporary, and even comprise a relatively small percentage of a dock's daily operations. Even a very active salt dock will likely only receive twenty ships per year, which collectively would only take one hundred days to unload.

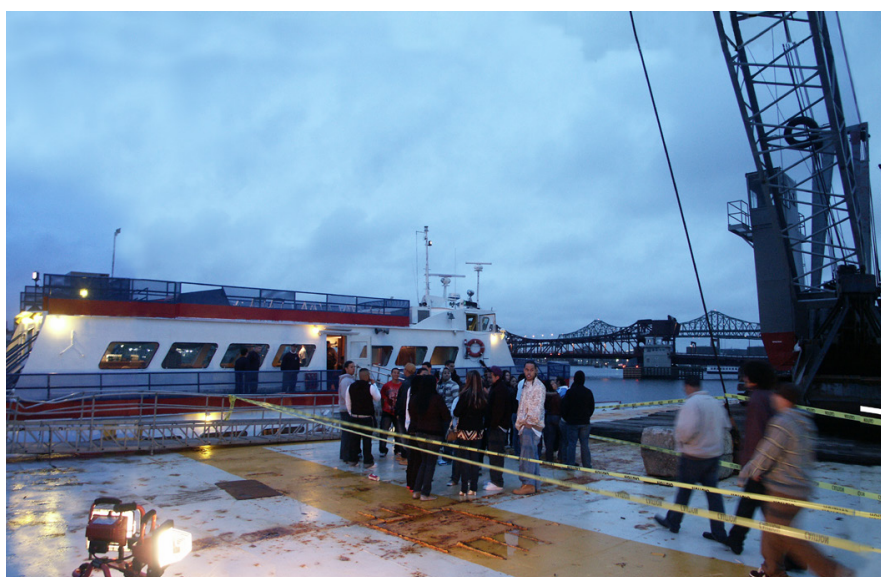

Figure 4: High school dance cruise setting off from crane barge, Chelsea, MA 

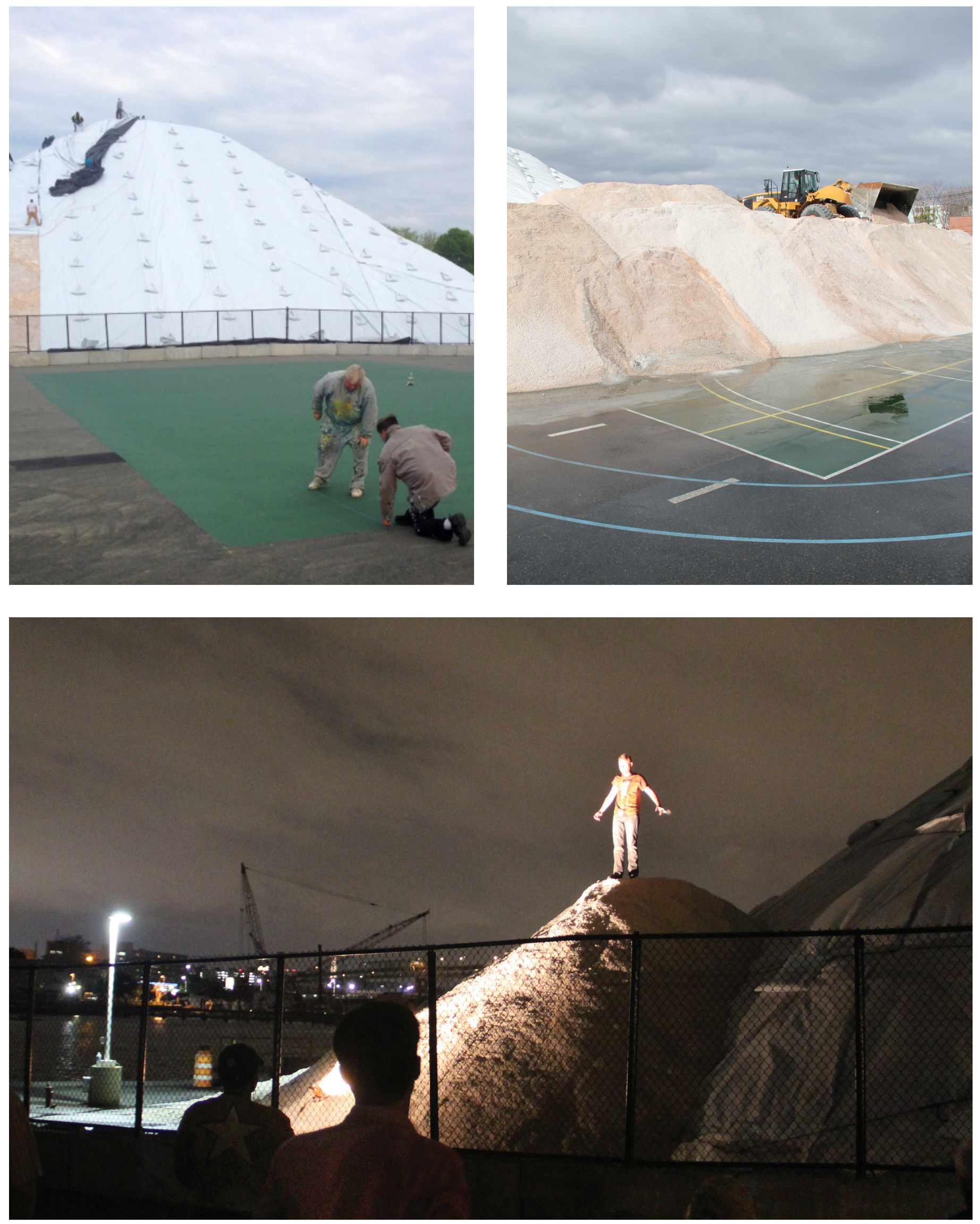

Figure 5: Preparing basketball court and scenes from Hamlet on the salt pile, Chelsea, MA 
This means that such a site could have no security restrictions at all for more than two thirds of the year.

Like the basketball example highlighted above, the Rock Chapel Marine terminal is designed to repurpose even the active maritime industrial infrastructure of the salt dock for public access and recreation during the times that the salt dock is not used for industrial purposes.

\section{OFFSITE MITIGATION}

Another conventional relationship crafted between industry and the city are practices enforced by government environmental agencies and local city planning offices to offset the impacts of industry through offsite mitigation.

As was the case in the aforementioned salt dock, the expansion of a salt terminal was tied to the funding of a soccer field resurfacing project that occurred elsewhere in the neighborhood, detached from the industry and its operations. While such projects create obvious amenities for the city, they do not inherently change the relationship between the industry and the city - or address the original basis for mitigation in the first place. Other examples of conventional modes of mitigation aim to buffer or shroud the operations of industry from the city through static architecture, such as sheds and fences.

In contrast, methods of mitigation can be developed to tune industrial operations to create new urban engagement. For example the same equipment that builds salt landscapes can also be used to create temporary public landscapes that would not be feasible in environments that are less rich with infrastructural capacity.

At Rock Chapel Marine, the terminal dock workers and machines relocate salt stockpiles, construct specifically designed salt landscapes, and reposition mobile fences and sporting equipment. Through the relocation of these temporary infrastructures, the salt dock can be alternately utilized by the industry in the winter months, and open to the public for events and recreation in the summer.

The ecology of industry and the city is structured by overly generic regulatory practices. A critical analysis of both those practices and the industrial operations can lead to new forms of engagement between industry and the city. Where industry is often treated as a globalized, homogenous standard, it is within the specificities of industrial operations and landscapes where opportunities for productive overlap can occur.

\section{ENDNOTES}

1. Kneen, Brewster, Invisible Giant: Cargill and its Transnational Strategies, (Pluto Press, 1995).

2. Sekula, Allen, Fish Story, (Richter Verlag, 1995), 49. 